\title{
Pathophysiology of diabetic dyslipidaemia: where are we?
}

\author{
Bruno Vergès
}

Received: 25 November 2014 / Accepted: 19 January 2015 / Published online: 1 March 2015

(C) The Author(s) 2015. This article is published with open access at Springerlink.com

\begin{abstract}
Cardiovascular disease is a major cause of morbidity and mortality in patients with type 2 diabetes mellitus, with a two- to fourfold increase in cardiovascular disease risk compared with non-diabetic individuals. Abnormalities in lipid metabolism that are observed in the context of type 2 diabetes are among the major factors contributing to an increased cardiovascular risk. Diabetic dyslipidaemia includes not only quantitative lipoprotein abnormalities, but also qualitative and kinetic abnormalities that, together, result in a shift towards a more atherogenic lipid profile. The primary quantitative lipoprotein abnormalities are increased triacylglycerol (triglyceride) levels and decreased HDL-cholesterol levels. Qualitative lipoprotein abnormalities include an increase in large, very low-density lipoprotein subfraction $1\left(\mathrm{VLDL}_{1}\right)$ and small, dense LDLs, as well as increased triacylglycerol content of LDL and HDL, glycation of apolipoproteins and increased susceptibility of LDL to oxidation. The main kinetic abnormalities are increased $\mathrm{VLDL}_{1}$ production, decreased VLDL catabolism and increased HDL catabolism. In addition, even though LDL-cholesterol levels are typically normal in patients with type 2 diabetes, LDL particles show reduced turnover, which is potentially atherogenic. Although the pathophysiology of diabetic dyslipidaemia is not fully understood, the insulin resistance and relative insulin deficiency observed in patients with type 2 diabetes are likely to contribute to these lipid changes, as insulin plays an important role in regulating lipid metabolism. In addition, some adipocytokines, such as adiponectin or
\end{abstract}

B. Vergès $(\bowtie)$

Service Endocrinologie, Diabétologie et Maladies Métaboliques,

Hôpital du Bocage, 2 bd Maréchal de Lattre de Tassigny,

21000 Dijon, France

e-mail: bruno.verges@chu-dijon.fr

$B$. Vergès

INSERM CRI 866, Medicine University, Dijon, France retinol-binding protein 4, may also contribute to the development of dyslipidaemia in patients with type 2 diabetes.

Keywords Cardiovascular disease $\cdot$ Dyslipidaemia . HDL-cholesterol (HDL-C) · Insulin resistance . LDL-cholesterol (LDL-C) · Lipid metabolism · Review · Triglycerides · Type 2 diabetes mellitus

$\begin{array}{ll}\text { Abbreviations } \\ \text { ABCA1 } & \text { ATP-binding cassette protein 1 } \\ \text { ABCG1 } & \text { ATP-binding cassette G1 } \\ \text { Apo } & \text { Apolipoprotein } \\ \text { ARF-1 } & \text { ADP ribosylation factor 1 } \\ \text { CETP } & \text { Cholesteryl ester transfer protein } \\ \text { ChREBP } & \text { Carbohydrate responsive element-binding } \\ & \text { protein } \\ \text { ER } & \text { Endoplasmic reticulum } \\ \text { FOXO1 } & \text { Forkhead box protein O1 } \\ \text { HMG-CoA } & \text { 3-Hydroxy-3-methylglutaryl coenzyme A } \\ \text { LCAT } & \text { Lecithin-cholesterol acyltransferase } \\ \text { ICAM-1 } & \text { Intercellular adhesion molecule 1 } \\ \text { IDL } & \text { Intermediate-density lipoprotein } \\ \text { LPL } & \text { Lipoprotein lipase } \\ \text { LRP } & \text { LDL receptor-related protein } \\ \text { MTP } & \text { Microsomal triacylglycerol transfer protein } \\ \text { PERPP } & \text { Post-ER presecretory proteolysis } \\ \text { PI3K } & \text { Phosphatidylinositol 3-kinase } \\ \text { PIP2 } & \text { Phosphatidylinositol 4,5-bisphosphate } \\ \text { PIP3 } & \text { Phosphatidylinositol 3,4,5-trisphosphate } \\ \text { PLTP } & \text { Phospholipid transfer protein } \\ \text { RBP4 } & \text { Retinol-binding protein 4 } \\ \text { PTP-1B } & \text { Protein-tyrosine phosphatase 1B } \\ \text { SREBP } & \text { Sterol regulatory element-binding protein } \\ & \end{array}$




\section{Introduction}

The risk of cardiovascular disease and cardiovascular mortality is significantly increased in patients with type 2 diabetes mellitus relative to healthy individuals $[1,2]$. A major contributor to the increased cardiovascular risk associated with type 2 diabetes is dyslipidaemia, which encompasses abnormalities in all lipoproteins [3-5]. Lipid abnormalities observed in type 2 diabetes are not only quantitative, but also qualitative and kinetic in nature [6-8]. A number of factors may contribute to the changes in lipid metabolism in patients with type 2 diabetes, including insulin resistance and/or relative insulin deficiency, adipocytokines (e.g. adiponectin), and hyperglycaemia [6-8]. The aim of this review is to briefly describe normal lipoprotein metabolism, including the role of insulin, to describe the pathophysiology of the lipid abnormalities observed in individuals with type 2 diabetes, and to discuss how these lipid abnormalities relate to the development of cardiovascular disease.

\section{Overview of normal lipoprotein metabolism}

Lipids are transported within body fluids in the form of lipoprotein particles, which are classified according to their density, ranging from chylomicrons to VLDL, intermediatedensity lipoprotein (IDL), LDL and HDL (Fig. 1).

Postprandial lipidaemia and chylomicrons

Dietary lipids are absorbed by the enterocytes via passive diffusion or specific transporters (e.g. CD36 for NEFA and Niemann-Pick C1-like 1 protein [NPC1L1] for cholesterol). Within the enterocytes, triacylglycerols (triglycerides), cholesteryl esters and other lipids (phospholipids and small amounts of unesterified cholesterol) are associated with apolipoprotein (Apo)B-48 (as well as ApoA-IV and ApoA-I) to form chylomicrons in a process involving microsomal triacylglycerol transfer protein (MTP) and fatty acid transport proteins. Chylomicrons are then exported into lymph and subsequently into the blood. ApoB-48 synthesis by the gut occurs continuously; however, lipidation to form chylomicrons is dependent on the availability of lipids and occurs mainly after meals.

Lipoprotein lipase (LPL), which is attached to the luminal surface of endothelial cells and present mostly in muscles, the heart and the adipose tissue, plays a major role in chylomicron clearance by hydrolysing triacylglycerols and liberating NEFA into the circulation.

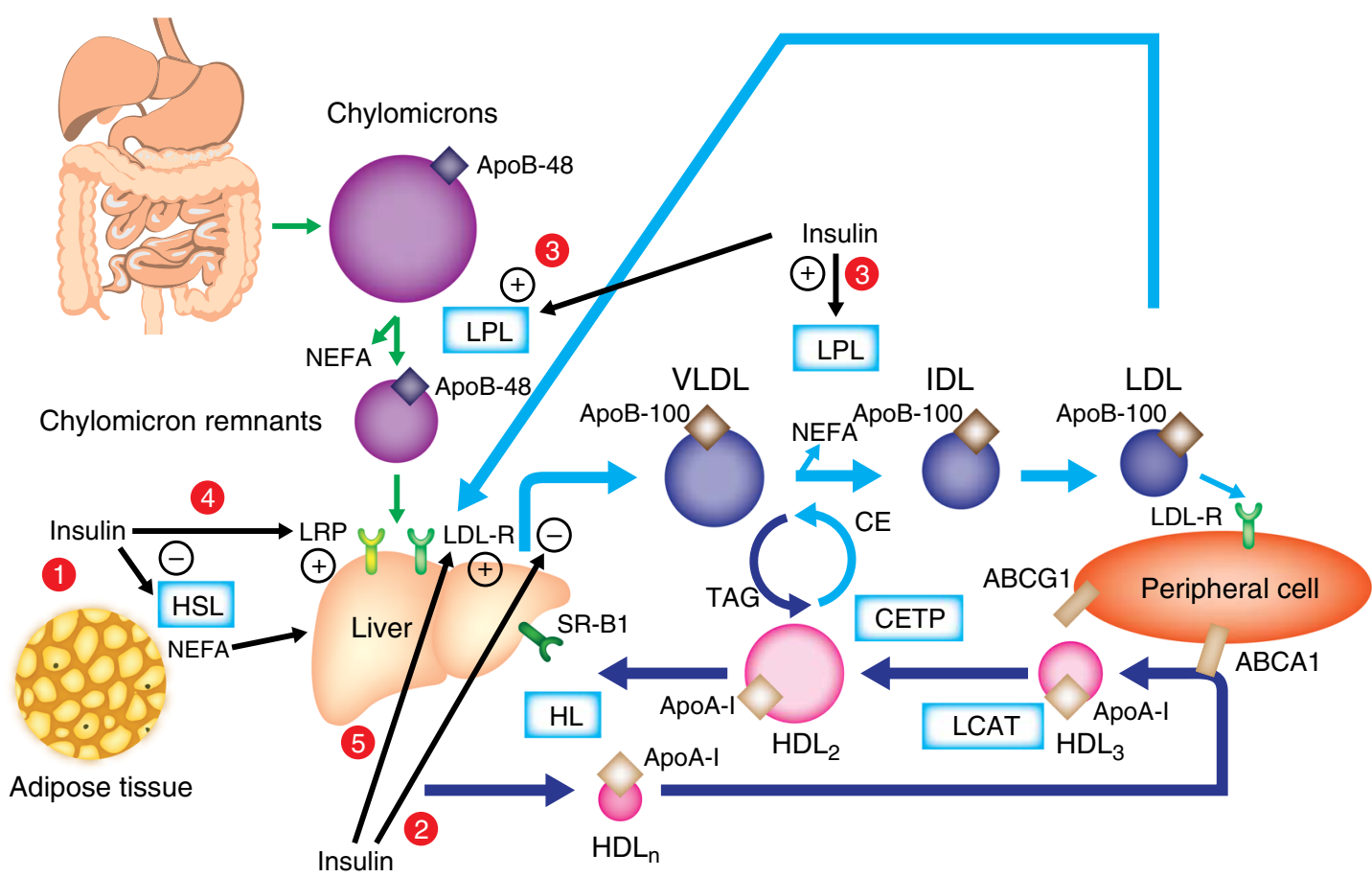

Fig. 1 An overview of human lipoprotein metabolism and the effects of insulin on lipoprotein metabolism. (1) Insulin inhibits hormone-sensitive lipase. (2) Insulin inhibits hepatic VLDL production. (3) Insulin activates LPL. (4) Insulin increases LRP expression on the plasma membrane. (5)

Insulin increases LDL receptor (LDL-R) expression. CE, cholesterol ester; CETP, cholesteryl ester transfer protein; $\mathrm{HDL}_{n}$, nascent HDL HL, hepatic lipase; HSL, hormone-sensitive lipase; LPL, lipoprotein lipase; SR-B1, scavenger receptor B1; TAG, triacylglycerol 
The chylomicron remnants produced by the lipolysis of chylomicrons are taken up by the liver via the LDL receptor (Fig. 1) in conjunction with the LDL receptor-related protein (LRP), both of which bind ApoE.

\section{VLDLs and IDLs}

Lipids are exported from the liver into the blood as VLDLs. The first step of VLDL assembly takes place in the rough endoplasmic reticulum (ER) where ApoB-100 is cotranslationally and post-translationally lipidated by MTP, forming pre-VLDL $[9,10]$. In the absence of adequate core lipids and/or MTP, partially translocated ApoB is exposed to the cytosol and subjected to degradation via the ubiquitinproteasome system. During the second step, pre-VLDL is further lipidated late in the ER compartment to form $\mathrm{VLDL}_{2}$, exiting the ER compartment via Sar1 (a GTPase)/coat protein II (COPII) vesicles that fuse to the cis side of the Golgi apparatus. In the Golgi apparatus, $\mathrm{VLDL}_{2}$ can be converted into larger $\mathrm{VLDL}_{1}$ by the addition of lipids (Fig. 2). At this stage, VLDL particles may also be degraded via post-ER presecretory proteolysis (PERPP) [11]. The formation of $\mathrm{VLDL}_{1}$ depends on factors such as ADP ribosylation factor 1 (ARF-1), phospholipase D1 and extracellular signalregulated kinase 2 (ERK2), which are involved in membrane trafficking between the ER and the Golgi apparatus or in the formation of cytosolic lipid droplets [10].
As with chylomicrons, triacylglycerols from VLDLs are hydrolysed by LPL in plasma, producing NEFA to be used as fuel in the heart and skeletal muscle or for storage within adipocytes (as triacylglycerols). The progressive triacylglycerol depletion of VLDLs induces the transfer of a portion of the lipoprotein surface layer (including phospholipids, ApoC and ApoE) to HDLs and leads to the formation of IDLs [8]. Approximately $90 \%$ of IDLs are converted into LDL through further lipolysis involving hepatic lipase, which has both triacylglycerol lipase and phospholipase activities, whereas the rest is cleared by the liver (via LRP or LDL receptors).

\section{LDLs}

LDL, the major transporter of cholesterol within the blood, comprises a core of esterified cholesterol molecules enclosed in a shell of phospholipids and unesterified cholesterol, together with a single molecule of ApoB-100. LDL is taken up into cells via receptor-mediated endocytosis, which involves, first, the binding of LDL-ApoB-100 to the LDL receptor on the plasma membrane of hepatic and other tissues, then the internalisation of the LDL-receptor complex via endocytosis, followed by fusion with lysozymes, which contain a number of catabolic enzymes. Proprotein convertase subtilisin/kexin type 9 (PCSK9) plays a key role in regulating LDL-receptor activity by binding the LDL-receptor/LDL complex and directing the receptor away from recycling back to the surface and into the lysosomal catabolic pathway.
Fig. 2 An overview of VLDL assembly and secretion. Step 1: In the rough ER, ApoB is lipidated by MTP, leading to the formation of pre-VLDL, then $\mathrm{VLDL}_{2}$ by further lipidation. $\mathrm{VLDL}_{2}$ exits the ER compartment via Sar1/COPII vesicles, which are directed to the Golgi apparatus. ARF-1 is involved in VLDL 2 trafficking between the ER and the Golgi apparatus. Step 2: In the Golgi apparatus, $\mathrm{VLDL}_{2}$ is converted into larger $\mathrm{VLDL}_{1}$ by the addition of lipids. This step is promoted by phospholipase D1 and extracellular signal-regulated kinase 2 (ERK2). At this stage degradation by PERPP may occur. COPII, coat protein II; FA, fatty acid; MTP, microsomal triglyceride transfer protein; TAG, triacylglycerol

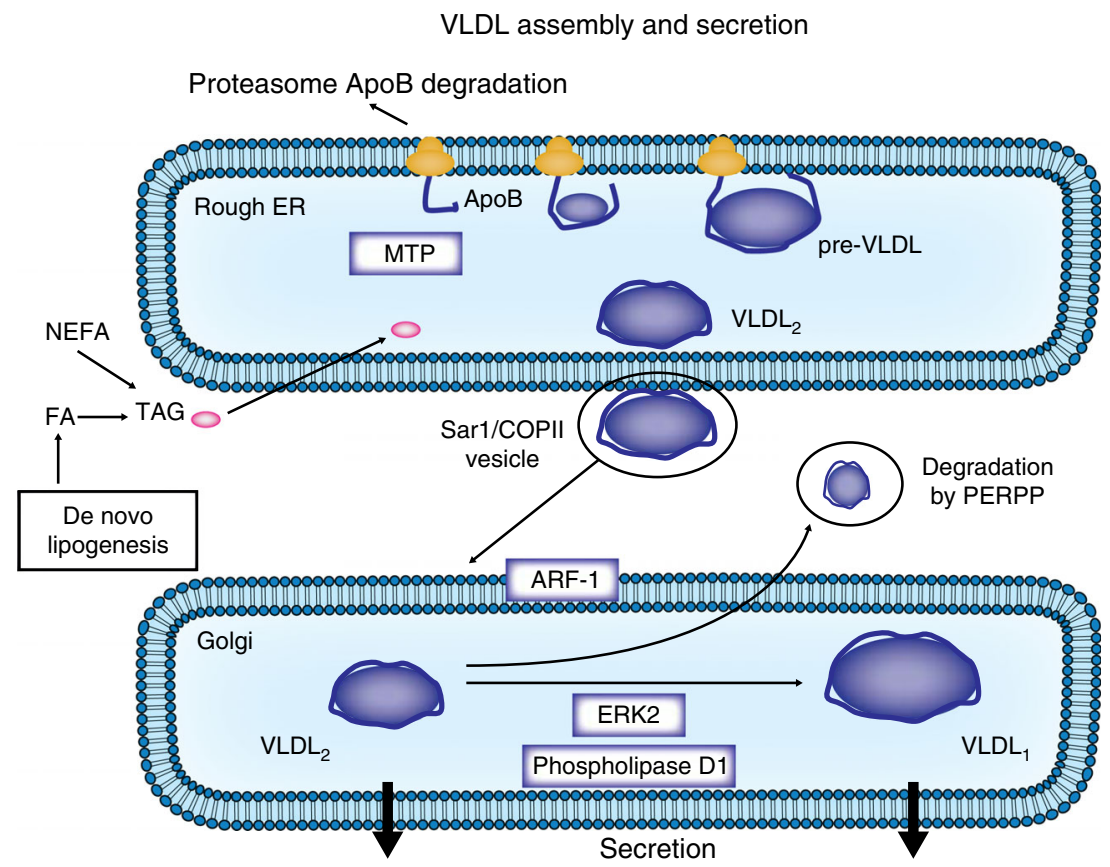


HDLs

The atheroprotective effect of HDLs related to their role in reverse cholesterol transport is well known, but these lipoprotein particles also have anti-inflammatory, antioxidative, anti-thrombotic and anti-apoptotic properties. HDLs are synthesised by both the liver and the intestine. Newly secreted or nascent HDLs contain only apolipoproteins (mainly ApoA-I) and rapidly recruit nonesterified cholesterol and phospholipids from peripheral cells through the binding of ApoA-I to the membraneassociated ATP-binding cassette protein 1 (ABCA1) transporter, allowing for the transport of non-esterified cholesterol and phospholipids from the cytoplasm into HDL (Fig. 1) [12]. Within the HDL particle, nonesterified cholesterol is esterified by lecithin-cholesterol acyltransferase (LCAT). In the circulation, HDLs acquire more cholesterol from peripheral tissues, including macrophages within artery walls, again through the ABCA1 transporter, as well as the ATP-binding cassette G1 (ABCG1) transporter. During this process, small-size HDL (usually called $\mathrm{HDL}_{3}$ ) becomes larger (usually called $\mathrm{HDL}_{2}$ ). HDL returns cholesterol to the liver via both direct and indirect mechanisms. Through scavenger receptor B1 (SR-B1), HDL-cholesteryl esters are directly taken up by the liver, where they are hydrolysed. HDL also exchanges lipids with VLDL and LDL in a process involving cholesteryl ester transfer protein (CETP), whereby cholesteryl esters are transferred from HDL to VLDL and, reciprocally, triacylglycerols are transferred from VLDL to HDL. In the circulation, HDL also receives ApoC and ApoE from VLDL. In addition, phospholipid transfer protein (PLTP) promotes the transfer of phospholipids from VLDL to HDL. During this process, HDL becomes enriched in triacylglycerols and phospholipids that are both degraded by hepatic lipase, thus forming smaller HDL particles that can be cleared by the liver or again participate in reverse cholesterol transport. During the catabolic process, lipid-poor ApoA-I is formed that can be filtered at the level of the glomerulus and then catabolised by proximal renal tubular epithelial cells after binding to cubilin, a protein localised to the apical surface of the renal tubular cell [13].

\section{Lipid transfer proteins}

CETP and PLTP play key roles in lipoprotein metabolism. CETP facilitates the transport of cholesteryl esters and triacylglycerols between the lipoproteins, resulting in: (1) a net loss of cholesterol esters and gain of triacylglycerols by HDL and LDL; and (2) a reciprocal net gain of cholesterol esters and loss of triacylglycerols by chylomicrons and VLDL. CETP activity is increased by triacylglycerol-rich lipoproteins, NEFA and some phospholipids (phosphatidylcholine) and is inhibited by ApoC-I [14]. Any changes in CETP activity significantly modify the composition and metabolism of lipoproteins. PLTP circulates in the plasma bound to HDL, mediating the transfer of phospholipids (e.g. from VLDL remnants) into these particles, and also the exchange of phospholipids between lipoproteins.

\section{Adiponectin}

Adiponectin is thought to play a direct role in influencing lipid metabolism. Adiponectin has been shown to be inversely correlated with fasting and postprandial triacylglycerols $[15,16]$. It facilitates ApoA-I-mediated cholesterol efflux from macrophages by upregulating ABCA1 expression [17]. In addition, adiponectin is positively correlated with plasma HDL-cholesterol levels, and some data indicate that adiponectin may directly reduce HDL catabolism [18].

\section{The role of insulin in lipoprotein metabolism}

Insulin is a key hormone in the regulation of lipid metabolism. The main sites of action of insulin on lipoprotein metabolism are shown in Fig. 1. In adipose tissue, insulin has an antilipolytic effect, inhibiting hormonesensitive lipase. Thus, it promotes storage of triacylglycerols in adipocytes and reduces secretion of circulating NEFA from adipose tissue. This inhibition of lipolysis by insulin is particularly effective during the postprandial period.

Insulin directly inhibits hepatic VLDL production. In individuals with normal lipid metabolism, insulin has been shown to induce a $66 \%$ decrease in VLDLtriacylglycerol production and a $53 \%$ decrease in VLDL-ApoB production [19]. Insulin reduces VLDL production by diminishing circulating levels of NEFA, which are substrates for VLDL, and by exerting a direct inhibitory effect on VLDL production in hepatocytes [20]. There are several findings indicating that the phosphatidylinositol 3-kinase (PI3K) pathway is involved in the inhibitory effect of insulin on VLDL secretion. The binding of insulin to its receptor induces tyrosine phosphorylation of insulin receptor substrates leading to activation of PI3K, which, once activated, induces the transformation of phosphatidylinositol 4,5-bisphosphate (PIP2) into phosphatidylinositol 3,4,5-trisphosphate (PIP3), leading to promotion of the activation of Akt, a serine/threonine kinase implicated as an effector of metabolic actions of insulin. Indeed, insulin has been shown to inhibit, via PI3K, the maturation phase of 
VLDL assembly by preventing bulk lipid transfer to VLDL precursors $[21,22]$. This effect could be partly explained by the inhibition by insulin of phospholipase D1 and ARF-1, two factors involved in the formation of $\mathrm{VLDL}_{1}[6,10]$. In addition, insulin activation promotes the PERPP of ApoB via PI3K [23]. It has also been shown that insulin reduces the synthesis of ApoB by inhibiting $A p o B$ mRNA translation [24]. Furthermore, insulin negatively regulates MTP (also known as $M T T P)$ gene expression [10]. Insulin is a potent activator of LPL, promoting the catabolism of triacylglycerolrich lipoproteins (e.g. chylomicrons, VLDL) [15]. Insulin also inhibits the expression of ApoC-III, an inhibitor of LPL [25]. In addition, it induces the translocation of LRP to the plasma membrane, increasing the uptake and clearance of chylomicron remnants [26].

Insulin also promotes the clearance of LDL by increasing LDL-receptor expression and activity [27]. Some data indicate that insulin may stimulate the activity of hepatic lipase [28], but hepatic lipase responsiveness to insulin is still controversial [29]. A study on individuals without diabetes reported that insulin infusion did not exert any significant effects on LCAT or CETP activity [30].

\section{Lipid abnormalities in type 2 diabetes}

Dyslipidaemia in individuals with type 2 diabetes is very common, with a prevalence of $72-85 \%[3,31]$. This phenomenon is associated with a significantly increased risk of coronary artery disease relative to individuals without diabetes [3]. Lipid abnormalities observed in patients with type 2 diabetes play a central role in the development of atherosclerosis. These lipid abnormalities are not only quantitative, but also qualitative and kinetic in nature [6-8]. Increased triacylglycerols and reduced HDL-cholesterol are the main quantitative lipid abnormalities of diabetic dyslipidaemia. In addition, patients with type 2 diabetes show qualitative and kinetic abnormalities for all lipoproteins (see Text box) [6-8, 32]. All of these abnormalities are known to be risk factors for the development of atherosclerosis [33]. The main lipid abnormalities observed in type 2 diabetes are shown in Fig. 3.

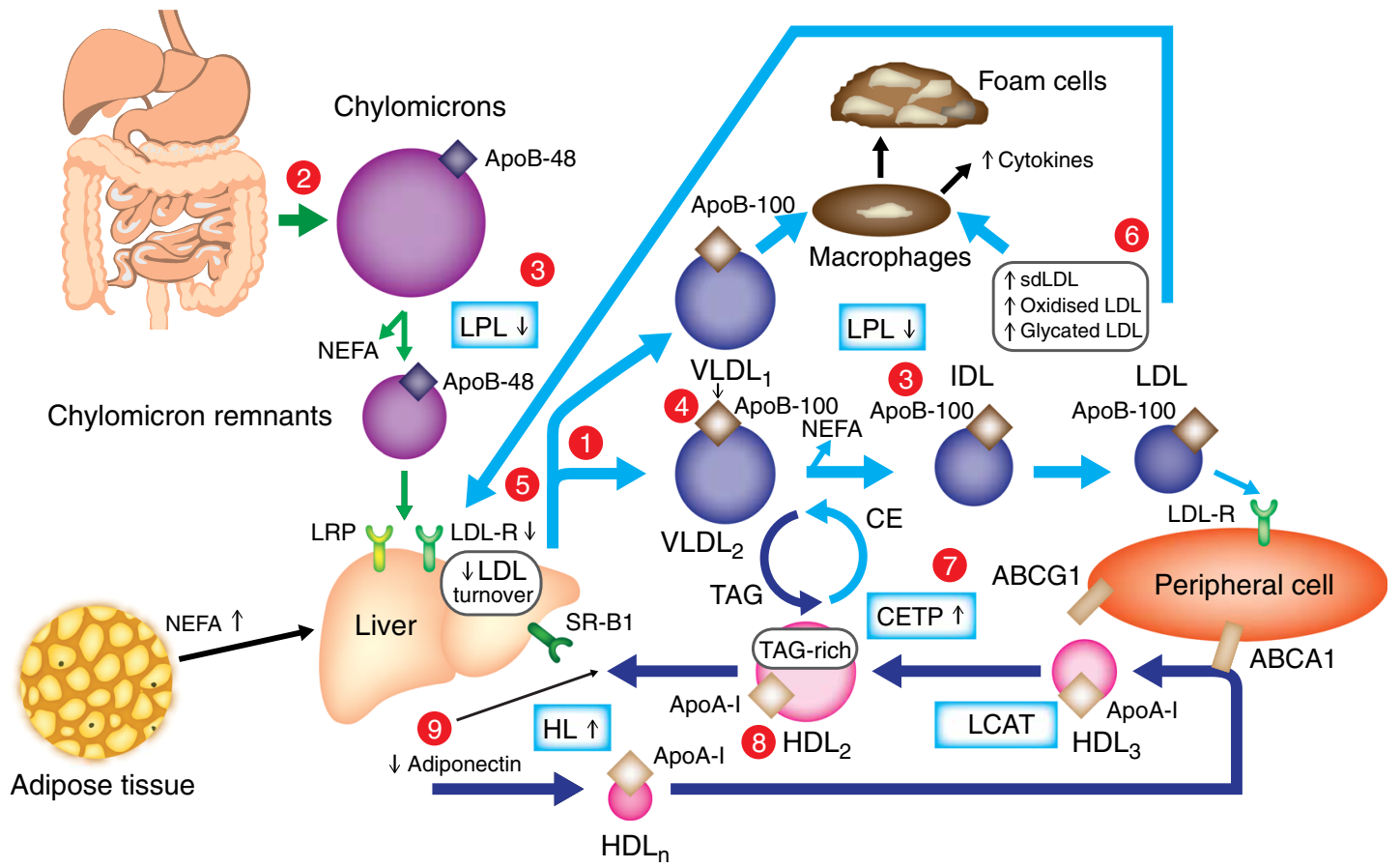

Fig. 3 Main lipid abnormalities in type 2 diabetes. Triacylglycerols (hypertriglyceridaemia, qualitative and kinetic abnormalities): (1) increased VLDL production (mostly $\mathrm{VLDL}_{1}$ ), (2) increased chylomicron production, (3) reduced catabolism of both chylomicrons and VLDLs (diminished LPL activity), (4) increased production of large VLDL (VLDL $)_{1}$ ), preferentially taken up by macrophages; LDL (qualitative and kinetic abnormalities): (5) reduced LDL turnover (decreased LDL $\mathrm{B} / \mathrm{E}$ receptor), (6) increased number of glycated LDLs, small, dense LDLs (TAG-rich) and oxidised LDLs, which are preferentially taken up

by macrophages; HDL (low HDL-cholesterol, qualitative and kinetic abnormalities): (7) increased CETP activity (increased transfer of triacylglycerols from TAG-rich lipoproteins to LDLs and HDLs), (8) increased TAG content of HDLs, promoting HL activity and HDL catabolism, (9) low plasma adiponectin favouring the increase in HDL catabolism. CE, cholesterol esters; CETP, cholesteryl ester transfer protein; dLDL, small, dense LDL; HDL ${ }_{n}$, nascent HDL; HL, hepatic lipase; HSL, hormone-sensitive lipase; LPL, lipoprotein lipase; sLDL-R, LDL receptor; SR-B1, scavenger receptor B1; TAG, triacylglycerol 


\begin{tabular}{|c|c|c|c|}
\hline \multicolumn{4}{|c|}{ Key changes in lipoprotein metabolism in type 2 diabetes } \\
\hline Lipoprotein & Quantitative changes & Qualitative changes & Kinetic/metabolic changes \\
\hline Chylomicron & $\begin{array}{l}\text { - Increased plasma } \\
\text { concentration }\end{array}$ & $\begin{array}{l}\text { - Very few data (decreased ApoE content in } \\
\text { diabetic rabbits) }\end{array}$ & $\begin{array}{l}\text { - Increased production } \\
\text { - Decreased catabolism }\end{array}$ \\
\hline VLDL & $\begin{array}{l}\text { - Increased plasma } \\
\text { concentration }\end{array}$ & $\begin{array}{l}\text { - Greater proportion of larger particles } \\
\left(\text { VLDL }_{1}\right) \\
\text { - Increased palmitic acid-containing species } \\
\text { and diacylglycerol, reduced sphingomyelin } \\
\text { - Glycation }\end{array}$ & $\begin{array}{l}\text { - Increased production } \\
\text { - Decreased catabolism }\end{array}$ \\
\hline LDL & $\begin{array}{l}\text { - No change or slightly } \\
\text { increased plasma } \\
\text { concentration }\end{array}$ & $\begin{array}{l}\text { - Greater proportion of small, dense particles } \\
\text { (triacylglycerol enrichment) } \\
\text { - Increased LDL oxidation } \\
\text { - Increased palmitic acid-containing species } \\
\text { and diacylglycerol, reduced sphingomyelin } \\
\text { - Glycation }\end{array}$ & - Decreased catabolism \\
\hline HDL & $\begin{array}{l}\text { - Decreased plasma } \\
\text { concentration }\end{array}$ & $\begin{array}{l}\text { - Triacylglycerol enrichment } \\
\text { - Reduced phospholipids, ApoE and ApoM } \\
\text { - Glycation }\end{array}$ & - Increased catabolism \\
\hline
\end{tabular}

It is important to note that many of the lipid abnormalities observed in patients with type 2 diabetes exist before the onset of diabetes as part of the insulin-resistant metabolic syndrome which is characterised by the accumulation of triacylglycerolrich lipoproteins and small, dense LDL particles with reduced HDL-cholesterol in plasma. These lipid abnormalities are known to promote cardiovascular disease in individuals with the metabolic syndrome [34]. This emphasises the important role of insulin resistance in the pathophysiology of diabetic dyslipidaemia, which is also highlighted by the presence of lipid abnormalities typical of diabetic dyslipidaemia in nondiabetic insulin-resistant first-degree relatives of patients with type 2 diabetes $[35,36]$.

\section{Cholesterol absorption and synthesis}

Patients with type 2 diabetes have a reduced plasma level of campesterol, a marker of cholesterol absorption, and increased plasma levels of lathosterol, a marker of cholesterol synthesis [37]. Using peroral administration of isotopes, reduced cholesterol absorption and increased cholesterol synthesis have been demonstrated in patients with type 2 diabetes [38]. The mechanisms responsible for these changes in cholesterol homeostasis are not yet clarified. In a study performed in 263 patients with type 2 diabetes, liver fat content was independently associated with plasma lathosterol [39]. It has been suggested that this could be due to increased expression of $S R E B P 2$, encoding sterol regulatory element-binding protein, a factor regulating cholesterol uptake and synthesis, observed under conditions of increased liver fat content [40].
Postprandial hyperlipidaemia and chylomicrons

In individuals with type 2 diabetes and insulin resistance, an increase in chylomicron production is observed, contributing to the postprandial hyperlipidaemia observed in this population [41]. Indeed, patients with type 2 diabetes have an increased rate of intestinal ApoB-48 secretion [42] and augmented expression of MTP (responsible for the addition of triacylglycerols to ApoB-48) within the intestine [43]. Insulin resistance is likely to be involved in the increased chylomicron production, since the normal acute suppression of postprandial chylomicron secretion, by insulin, is absent in patients with type 2 diabetes [44]. In addition, increased plasma NEFA concentrations (as a result of reduced inhibition of hormone-sensitive lipase in type 2 diabetes [45]) may further drive ApoB-48 secretion [46]. The clearance of chylomicrons is also impaired in type 2 diabetes [47]. Several mechanisms are responsible for this delayed chylomicron catabolism. The activity of LPL, the enzyme responsible for chylomicron hydrolysis, is significantly reduced in patients with type 2 diabetes [15, 48]. Insulin resistance is also associated with increased plasma levels of ApoC-III, an inhibitor of LPL [49]. Furthermore, the activation of LRP (one of the hepatic receptors responsible for chylomicron remnant uptake) by insulin is abolished in insulin-resistant mice [26]. The net result of all these changes is a significantly larger pool of chylomicrons (hypertriglyceridaemia) (Fig. 3). Moreover, patients with type 2 diabetes show increased levels of atherogenic remnant particles, including chylomicron remnants and VLDL remnants [50]. 
Postprandial hyperlipidaemia is likely to promote atherosclerosis and the occurrence of cardiovascular events in patients with type 2 diabetes. The increase in postprandial triacylglycerols has been shown to be correlated with the increase in TNF $\alpha$, IL- 6 and vascular cell adhesion molecule 1 (VCAM-1) values, in patients with type 2 diabetes, indicating a deleterious proinflammatory effect of postprandial hyperlipidaemia [51]. Furthermore, the magnitude of postprandial hypertriglyceridaemia is strongly correlated with the reduction in flow mediated dilatation, in patients with type 2 diabetes, indicating a role for postprandial hyperlipidaemia in endothelial dysfunction [52].

\section{VLDLs and IDLs}

Increased plasma triacylglycerol levels in patients with type 2 diabetes are largely due to an increased number of VLDLs, particularly large $\mathrm{VLDL}_{1}$ particles [6]. Both increased production and delayed catabolism of VLDL are responsible for the increased VLDL pool. In vivo kinetic studies in patients with type 2 diabetes have shown an augmented production of both VLDL-ApoB and VLDL-triacylglycerols [53-55]. More precisely, it has been demonstrated that type 2 diabetes is associated with increased production of large $\mathrm{VLDL}_{1}$ particles [56, 57]. Similar increases in VLDL production have been observed in obese, non-diabetic, insulin-resistant individuals, suggesting a critical role of insulin resistance in the pathophysiology of VLDL overproduction in type 2 diabetes [58, 59]. It has been shown that the $\mathrm{VLDL}_{1}$ production rate is correlated with insulin resistance and liver fat in patients with type 2 diabetes [57, 60].

Insulin resistance is associated with reduced inhibition of hormone-sensitive lipase in adipose tissue by insulin, leading to increased lipolysis and, thereby, augmented NEFA portal flux to the liver. This has been shown to stimulate synthesis of triacylglycerols in hepatocytes [10]. Furthermore, the normal suppressant effect of insulin on postprandial VLDL (more specifically, $\mathrm{VLDL}_{1}$ ) production is blunted by hepatic insulin resistance $[45,56,61]$. Several mechanisms seem to be involved in the overproduction of hepatic VLDL relative to the reduced inhibitory effect of insulin (Fig. 4). First, data from animal studies have provided evidence that insulin resistance is associated with a reduction in ApoB degradation in hepatocytes, leading to an increase in the ApoB pool available for VLDL assembly [62, 63]. Reduced PI3K activity in animal models, secondary to insulin resistance, has been reported to increase the expression of protein-tyrosine phosphatase 1B (PTP-1B), leading to suppression of ER60, a protease associated with the ER, which promotes ApoB degradation via a non-proteasomal pathway $[62,64]$. In addition, an increased NEFA level in hepatocytes reduces the post-translational degradation of ApoB. Second, MTP expression is increased in insulin-resistant states and type 2 diabetes [65]. In insulin resistance, the reduced activation of PI3K leads to increased forkhead box protein $\mathrm{O} 1$ (FOXO1) activation, which is normally inhibited by activated PI3K. This increased activation of FOXO1 is responsible for augmented transcription of the MTP gene [66]. Third, it has been suggested that insulin resistance could be responsible for the increased activity of two factors involved in the formation of $\mathrm{VLDL}_{1}$ : phospholipase D1 and ARF-1 [21]. It has also been suggested that decreased PIP3, secondary to reduced PI3K activation, may also be involved, since PIP3, a highly negatively charged phospholipid, reduces lipid transfer to VLDL precursor and, thus, the formation of $\mathrm{VLDL}_{1}$ [22]. It is possible that the increased formation of $\mathrm{VLDL}_{1}$ automatically reduces the amount of VLDL precursors available for PERPP and, thus, decreases the rate of ApoB degradation [22].

In addition, de novo lipogenesis is increased in individuals with insulin resistance [67]. This increased de novo lipogenesis is secondary to augmented expression of both carbohydrate responsiveness element-binding protein (ChREBP) and sterol regulatory element-binding protein (SREBP)- $1 \mathrm{c}$ in insulin resistance and type 2 diabetes [10]. It is suspected that, in patients with type 2 diabetes, hyperglycaemia directly activates ChREBP [68]. The increase in SREBP-1c expression could be related to the augmented ER stress observed in insulin resistance and type 2 diabetes [69]. Based on animal studies, it has been proposed that hyperinsulinaemia observed in insulin resistance and type 2 diabetes might be responsible for increased SREBP-1c expression because insulin stimulates SREBP-1c transcription. However, this is not supported by data in humans, since hyperinsulinaemia in patients with insulinoma is not associated with increased VLDL production [70]. Furthermore, insulin treatment in patients with type 2 diabetes induces a reduction in liver fat rather than an increase [71]. Moreover, reduced plasma adiponectin levels observed in type 2 diabetes may also promote VLDL production by increasing plasma NEFA levels, as a consequence of reduced muscle NEFA oxidation, and by inducing a decrease in AMP-kinase activation in the liver, which promotes de novo lipogenesis [10].

As assessed by kinetic studies using radioisotopes [54] and stable isotopes [53], catabolism of VLDLs is reduced in patients with type 2 diabetes, which also promotes hypertriglyceridaemia. This defect in VLDL catabolism mainly reflects the reduced activity of LPL in type 2 diabetes, particularly in adipose tissue [48]. Since insulin is an activator of LPL, it has been suggested that the diminution of LPL activity may be due to a relative insulin deficiency and/or insulin resistance. In addition, increased plasma levels of ApoC-III (an inhibitor of LPL) could also contribute to the decreased catabolism of VLDL in patients with type 2 diabetes, since increased plasma levels of ApoC-III were associated with impaired VLDL clearance in obese insulin-resistant men [72]. Moreover, postprandially, chylomicrons and VLDL compete for LPL, which 


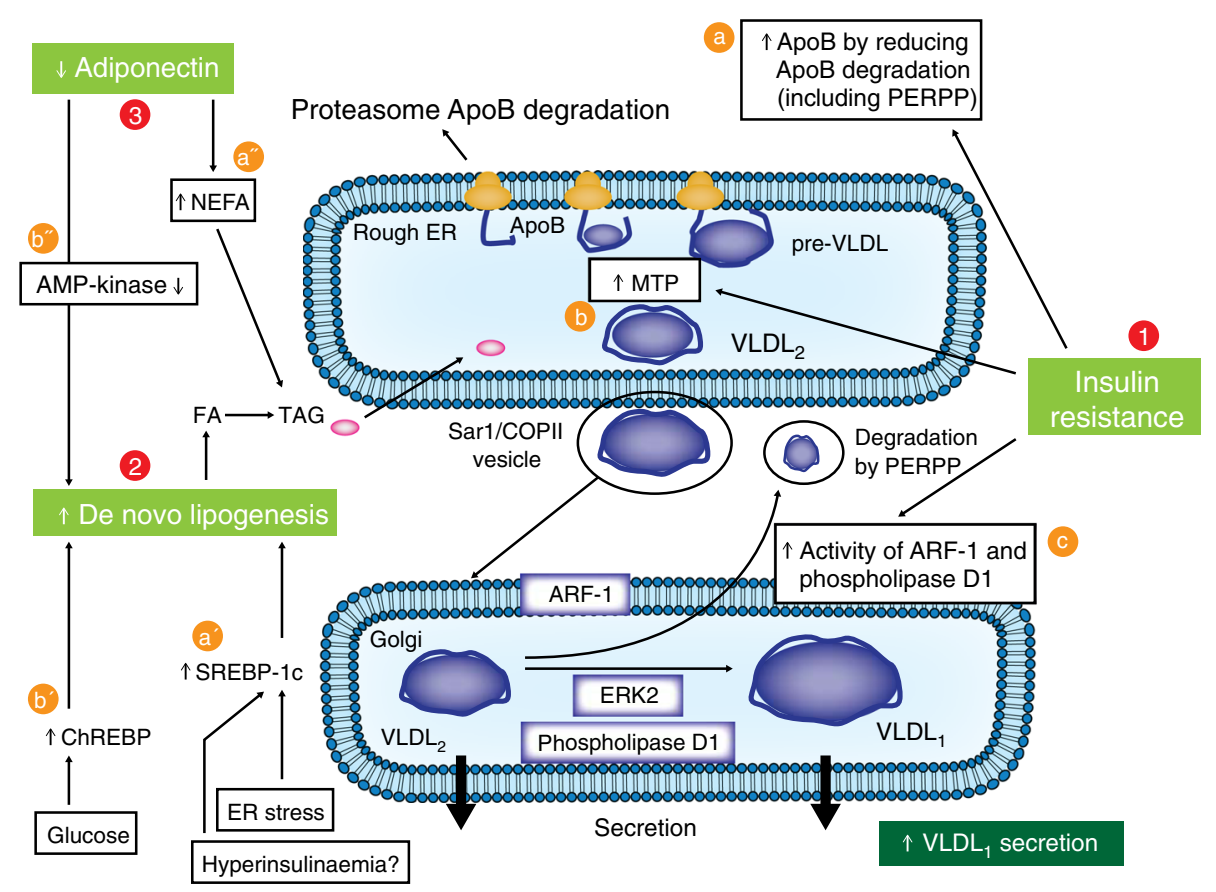

Fig. 4 Pathophysiology of increased hepatic VLDL production in type 2 diabetes. 1. Insulin resistance is responsible for: (a) a reduction in ApoB degradation, leading to an increased $A p o B$ level in hepatocytes (including ApoB degradation by PERPP); (b) increased MTP expression; and (c) increased activity of two factors involved in the formation of $\mathrm{VLDL}_{1}$, phospholipase D1 and ARF-1. Moreover, peripheral insulin resistance is responsible for increased levels of NEFA, which activate VLDL production (see $\left.\mathrm{a}^{\prime \prime}\right)$. 2. Increased de novo lipogenesis secondary to: ( $\left.\mathrm{a}^{\prime}\right)$ increased

exacerbates postprandial hypertriglyceridaemia. Most of the time, hypertriglyceridaemia observed in patients with type 2 diabetes is mild to moderate but the severity of hypertriglyceridaemia is also influenced, in each patient, by the genetic susceptibility [73]. In some sporadic cases of high genetic susceptibility, severe hypertriglyceridaemia may develop, with attendant risk of pancreatitis, particularly in hyperglycaemia [73].

The type of VLDL particles produced in type 2 diabetes is also altered, with a shift towards a greater proportion of those of a larger particle size $\left(\mathrm{VLDL}_{1}\right)[32,74]$. Relative to smaller VLDL particles, these are enriched with cholesterol esters and phospholipids. Larger triacylglycerol-enriched VLDL particles are potentially more atherogenic, as indicated by their significant association with endothelial dysfunction [52], and their preferential uptake by macrophages, leading to the formation of foam cells in vessel walls [75]. It has recently been demonstrated that VLDL from patients with type 2 diabetes has increased diacylglycerol content and reduced sphingomyelin, as well as increased palmitic acid-containing species [76]. Since palmitate is the major fatty acid synthesised during de novo lipogenesis, the increased palmitic acid content in VLDL-triacylglycerols might be a consequence of increased de novo lipogenesis, as suggested by a recent study that reported increased levels of circulating triacylglycerol- activation of SREBP-1c (by ER stress); and ( $\left.b^{\prime}\right)$ increased activation ChREBP (by hyperglycaemia). 3. Reduced plasma adiponectin level responsible for: $\left(\mathrm{a}^{\prime \prime}\right)$ increased plasma NEFA levels as a consequence of reduced muscle NEFA oxidation; and $\left(\mathrm{b}^{\prime \prime}\right)$ a reduction in AMP-kinase activation in the liver, which promotes de novo lipogenesis. COPII, coat protein II; ERK2, extracellular signal-regulated kinase 2; FA, fatty acid; TAG, triacylglycerol;

containing palmitic acid in insulin-resistant obese individuals with non-alcoholic fatty liver disease [77]. In addition, increased palmitic acid in VLDL-triacylglycerols has been shown to promote secretion of proinflammatory mediators by human smooth muscle cells [76]. Glycation of apolipoproteins in VLDL (ApoB, ApoCs, ApoE) may occur in diabetes. This may reduce VLDL binding to the $\mathrm{ApoB} / \mathrm{E}$ receptor and hence impair its catabolism [78]. Furthermore, it has been suggested that glycation of ApoC-II, a cofactor of LPL, could contribute to lesser LPL activation [79].

\section{LDLs}

In patients with type 2 diabetes, the mean LDL-cholesterol level is comparable or slightly elevated relative to that in individuals without diabetes $[6,8,32]$. However, the catabolism of LDL is substantially reduced [53, 80], inducing a longer duration of LDL in plasma that may promote lipid deposition within artery walls. In patients with type 2 diabetes, the number of LDL B/E cell-surface receptors is significantly reduced, which may be due to reduced insulin-mediated expression and could be responsible for observed impairments in LDL catabolism [81]. It has also been suggested that reduced LDL catabolism could be partly attributed to a decreased affinity of LDL for its receptor following ApoB glycation [82]. 
As a consequence of hyperglycaemia, increased glycation of LDL is observed in individuals with type 2 diabetes [83]. Glycated LDL has reduced affinity for LDL B/E receptors [84] and is preferentially taken up by macrophages, leading to the formation of foam cells [85]. Another lipoprotein modification observed in type 2 diabetes that has marked atherogenic potential is increased LDL oxidation. Patients with type 2 diabetes show increased oxidisability of LDLs and have an augmented number of oxidised LDL particles in their plasma [8]. Oxidised LDLs demonstrate a decreased affinity for the LDL receptor, and are preferentially taken into macrophages via specific oxidised LDL receptors prior to foam cell development [86]. In addition, they have chemoattractant effects on monocytes by increasing the formation of adhesion molecules, such as intercellular adhesion molecule 1 (ICAM-1), by endothelial cells, and by stimulating the formation of cytokines, such as TNF $\alpha$ or IL-1, by macrophages, which amplifies the inflammatory atherosclerotic process [86].

Small, dense, triacylglycerol-rich LDL particles (known as subclass B particles) are more prevalent in type 2 diabetes [87]. This is mainly related to hypertriglyceridaemia, and $\mathrm{VLDL}_{1}$ triacylglycerol is the major predictor of LDL size in patients with type 2 diabetes and in non-diabetic individuals [6]. The characteristic hypertriglyceridaemia observed in patients with type 2 diabetes stimulates CETP, leading to the preferential formation of triacylglycerol-rich small, dense LDL particles over larger ones [74]. The presence of small, dense LDL particles has been reported to be associated with increased cardiovascular risk and progression of atherosclerosis [88]. Small, dense LDL particles are more atherogenic. They are more likely to undergo glycation and oxidation than larger LDL particles, which promotes the generation of foam cells $[8,89]$. In addition, they show increased affinity for intimal proteoglycans, which may favour the penetration of LDLs into the arterial wall [90]. Individuals with small, dense LDL particles have an impaired response to the endotheliumdependent vasodilator acetylcholine [91]. Furthermore, as with VLDL, LDL from patients with type 2 diabetes shows significant changes in both lipid class (increased diacylglycerol and reduced sphingomyelin) and lipid species (increased palmitic acid-containing species), and the level of palmitic acid in LDL is correlated with insulin resistance [76].

\section{HDLs}

Plasma levels of HDL-cholesterol and ApoA-I are reduced in patients with type 2 diabetes [6-8]. In particular, the proportion of circulating smaller HDL particles $\left(\mathrm{HDL}_{3}\right)$ is increased, while there are far fewer large HDL particles $\left(\mathrm{HDL}_{2}\right)$; therefore, the overall number of HDL particles is reduced [74]. Reduced levels of $\mathrm{HDL}_{2}$ in patients with type 2 diabetes have been reported to be associated with both hypertriglyceridaemia and obesity [92]. Kinetic studies using radioisotopes [93] and stable isotopes [94] have demonstrated that the decrease in HDL-cholesterol in patients with type 2 diabetes is due to increased catabolism of HDLs. The activity of hepatic lipase, the enzyme controlling HDL catabolism, is augmented in insulin-resistant states, which is likely to be responsible for the observed increase in HDL catabolism [95]. Hypertriglyceridaemia is a major contributing factor to the accelerated HDL catabolism observed in type 2 diabetes. It has recently been demonstrated that both increased VLDL production and reduced $\mathrm{VLDL}_{1}$ catabolism are independent factors associated with increased HDL catabolism in insulinresistant states [96]. It is suggested that the increased pool of triacylglycerol-rich lipoproteins (mainly $\mathrm{VLDL}_{1}$ ), observed in type 2 diabetes, promotes CETP-mediated triacylglycerol enrichment of HDL particles and, as a consequence, enhances HDL catabolism, since HDL-rich particles are very good substrates for hepatic lipase. The reduction in plasma adiponectin levels observed in individuals with insulin resistance and type 2 diabetes may be another mechanism involved in the diminution of HDL-cholesterol levels. Indeed, a significant negative correlation has been reported between the rate of HDL-ApoA-I catabolism and plasma levels of adiponectin, independently of abdominal obesity, insulin sensitivity, age, sex and plasma lipids, suggesting a direct effect of adiponectin on HDL metabolism [18]; however, its precise role has yet to be determined.

Several qualitative abnormalities in HDLs have been described in patients with type 2 diabetes. They are enriched in triacylglycerols, and this enrichment is responsible for increased HDL catabolism, as previously discussed. Furthermore, HDLs are glycated in type 2 diabetes, although the exact consequences of this glycation remain unknown. The reduction in phospholipids in large HDL particles in patients with type 2 diabetes is associated with increased arterial stiffness [97]. Patients with type 2 diabetes also have reduced ApoE content in large HDL particles, which may have an atherogenic effect, since large, ApoE-rich HDL usually prevents LDL binding to proteoglycans in the vessel wall [97]. ApoM, which is mainly associated with HDL, is reduced in patients with type 2 diabetes due to diabetes-associated obesity $[97,98]$. ApoM promotes the formation of pre- $\beta$-HDL from $\alpha-\mathrm{HDL}$, and lower levels of ApoM may explain why pre- $\beta$-HDL formation is not increased in type 2 diabetes, despite increased PLTP activity. ApoM mediates the enrichment in sphingosine-1-phosphate in HDL, which promotes arterial vasodilation by stimulating endothelial nitric oxide formation [99].

In patients with type 2 diabetes, HDL has a reduced capacity to promote ex vivo cholesterol efflux from cells. This may be due to reduced expression of ABCA1, which is the membrane transporter responsible for the first step of cholesterol transfer from cell membranes to HDL [100]. Furthermore, glycation of ABCA1 has been shown to reduce its activity 
[101]. In addition, expression of ABCG1, another transporter involved in reverse cholesterol transport, is reduced in monocytes from patients with type 2 diabetes, and this is associated with impaired cholesterol efflux [102].

Reductions in the antioxidative effects of HDLs, promoted by hyperglycaemia and triacylglycerol enrichment, have been reported in patients with type 2 diabetes [103]. Furthermore, the ability of HDL to counteract the inhibition of endotheliumdependent vasorelaxation induced by oxidised LDL is impaired in type 2 diabetes. This reduction in HDL vasorelaxant effects is inversely correlated with HDL triacylglycerol content [104]. In line with these data, HDL from patients with type 2 diabetes has a weaker stimulatory effect on endothelial nitric oxide synthesis [105].

\section{Lipid transfer proteins}

The qualitative lipoprotein abnormalities observed in patients with type 2 diabetes, such as increased triacylglycerol content of LDL and HDL particles, indicate increased CETP activity [106]. The main factor responsible for the increased CETP activity in type 2 diabetes is the augmented pool of triacylglycerol-rich lipoproteins (mainly VLDL), which directly stimulate CETP. However, hyperglycaemia per se could also activate CETP, since glycation of lipoproteins increases CETP activity [107]. In addition, a recent study in patients with diabetes reported that glycation of ApoC-I reduces its inhibitory effect on CETP [108]. Increased PLTP mass and PLTP activity have also been reported in patients with type 2 diabetes [109], and this is associated with increased intimamedia thickness [110].

A putative role of some adipocytokines and proteins in the pathophysiology of diabetic dyslipidaemia?

Adiponectin Adiponectin has a generally anti-atherogenic profile that may be partly due to its beneficial action on lipid metabolism [111]. However, adiponectin levels are reduced in patients with type 2 diabetes, and so its cardioprotective effects are minimised.

In non-diabetic individuals, as in patients with type 2 diabetes, plasma adiponectin is negatively correlated with plasma triacylglycerols and positively correlated with plasma HDLcholesterol, and these associations are independent of insulin resistance [16, 112]. Low adiponectin plasma levels are associated with augmented VLDL catabolism [113] and coupled with reduced LPL activity in adipose tissue [114] independently of insulin resistance, suggesting a possible direct action of adiponectin on lipid metabolism, independent of its effects on insulin sensitivity. Adiponectin may decrease plasma triacylglycerols by enhancing NEFA oxidation or by stimulating lipoprotein lipase $[111,115]$. In addition, a significant negative correlation has been reported between HDL-ApoA-I catabolism and plasma adiponectin, independent of insulin resistance and plasma lipids, suggesting a direct effect of adiponectin on HDL metabolism [18]. However, the exact mechanisms that may explain a direct effect of adiponectin on VLDL and HDL have not yet been clarified.

Retinol-binding protein 4 Levels of retinol-binding protein 4 (RBP4), an adipokine secreted by adipocytes and the liver, are elevated in type 2 diabetes. An independent association between RBP4 and triacylglycerols has been reported [116, 117]. Moreover, a strong, independent, negative association has been reported between plasma RBP4 and VLDL catabolism in patients with type 2 diabetes, suggesting that RBP4 may be involved in the pathophysiology of hypertriglyceridaemia in type 2 diabetes [117]. Further studies are needed to clarify the potential role of RBP4 in diabetic dyslipidaemia.

\section{Conclusions}

Abnormalities of lipoprotein metabolism are one of the major factors contributing to cardiovascular risk in patients with type 2 diabetes, and diabetic dyslipidaemia includes not only quantitative but also qualitative and kinetic lipoprotein abnormalities that are inherently atherogenic. The primary (characteristic) quantitative abnormalities are hypertriglyceridaemia, accompanied by prolonged postprandial hyperlipidaemia and increased levels of remnant particles (related to the increased production of triacylglycerol-rich lipoproteins and a reduction in the rate of catabolism of triacylglycerol-rich lipoproteins), and decreased HDLcholesterol levels secondary to an increased rate of HDL catabolism. The most frequent qualitative abnormalities, which are potentially atherogenic, include an increase in large VLDL particle size $\left(\mathrm{VLDL}_{1}\right)$; a greater proportion of small, dense LDL particles; an augmented susceptibility of LDLs to oxidation; an increase in triacylglycerol content of both LDL and HDL; and glycation of apolipoproteins. Although levels of LDL may be normal in patients with type 2 diabetes, LDL plasma residence time is increased due to a slower turnover rate, and this may infer the promotion of lipid deposition within artery walls. Furthermore, the usual cardioprotective effects of HDL are reduced or abolished in type 2 diabetes. Some factors, such as insulin resistance and possibly some adipokines (e.g. adiponectin) and hyperglycaemia, are involved in the pathophysiology of diabetic dyslipidaemia. However, many questions remain unanswered (such as the pathophysiology and the consequences of the qualitative lipid abnormalities, the precise mechanisms and signalling pathways involved in the insulin resistance linked lipid abnormalities, the potential role of adipose tissue and adipocytokines in the pathophysiology of diabetic dyslipidaemia) and additional 
studies are needed to gain further insight into the precise mechanisms of diabetic dyslipidaemia. Deeper understanding of lipid disorders in type 2 diabetes should lead to better treatment of diabetic dyslipidaemia.

Acknowledgements Editorial support was provided by Lisa Shannon of MedErgy, and was funded by Janssen Pharmaceutica NV. The author retained full editorial control over the content of the article.

Funding Editorial support was provided by Lisa Shannon of MedErgy, and was funded by Janssen Pharmaceutica NV.

Duality of interest The author declares that there is no duality of interest associated with this manuscript.

Contribution statement BV provided substantial contributions to the conception of the manuscript, drafted and revised the manuscript critically for intellectual content, and approved the final version of the manuscript.

Open Access This article is distributed under the terms of the Creative Commons Attribution License which permits any use, distribution, and reproduction in any medium, provided the original author(s) and the source are credited.

\section{References}

1. Norgaard ML, Andersen SS, Schramm TK et al (2010) Changes in short- and long-term cardiovascular risk of incident diabetes and incident myocardial infarction - a nationwide study. Diabetologia 53:1612-1619

2. Mulnier HE, Seaman HE, Raleigh VS et al (2008) Risk of myocardial infarction in men and women with type 2 diabetes in the UK: a cohort study using the General Practice Research Database. Diabetologia 51:1639-1645

3. Turner RC, Millns H, Neil HA et al (1998) Risk factors for coronary artery disease in non-insulin dependent diabetes mellitus: United Kingdom Prospective Diabetes Study (UKPDS: 23). BMJ 316: 823-828

4. McEwen LN, Karter AJ, Waitzfelder BE et al (2012) Predictors of mortality over 8 years in type 2 diabetic patients: Translating Research Into Action for Diabetes (TRIAD). Diabetes Care 35:1301-1309

5. Eliasson B, Cederholm J, Eeg-Olofsson K, Svensson AM, Zethelius B, Gudbjornsdottir S (2011) Clinical usefulness of different lipid measures for prediction of coronary heart disease in type 2 diabetes: a report from the Swedish National Diabetes Register. Diabetes Care 34:2095-2100

6. Taskinen MR (2003) Diabetic dyslipidaemia: from basic research to clinical practice. Diabetologia 46:733-749

7. Chahil TJ, Ginsberg HN (2006) Diabetic dyslipidemia. Endocrinol Metab Clin North Am 35:491-510, vii-viii

8. Vergès B (2005) New insight into the pathophysiology of lipid abnormalities in type 2 diabetes. Diabetes Metab 31:429-439

9. Olofsson SO, Stillemark-Billton P, Asp L (2000) Intracellular assembly of VLDL: two major steps in separate cell compartments. Trends Cardiovasc Med 10:338-345

10. Vergès B (2010) Abnormal hepatic apolipoprotein B metabolism in type 2 diabetes. Atherosclerosis 211:353-360
11. Fisher EA, Pan M, Chen X et al (2001) The triple threat to nascent apolipoprotein B. Evidence for multiple, distinct degradative pathways. J Biol Chem 276:27855-27863

12. Ji A, Wroblewski JM, Cai L, de Beer MC, Webb NR, van der Westhuyzen DR (2012) Nascent HDL formation in hepatocytes and role of ABCA1, ABCG1, and SR-BI. J Lipid Res 53:446-455

13. Rader DJ (2006) Molecular regulation of HDL metabolism and function: implications for novel therapies. J Clin Invest 116:3090-3100

14. Pillois X, Gautier T, Bouillet B et al (2012) Constitutive inhibition of plasma CETP by apolipoprotein C1 is blunted in dyslipidemic patients with coronary artery disease. J Lipid Res 53:1200-1209

15. Cianflone K, Paglialunga S, Roy C (2008) Intestinally derived lipids: metabolic regulation and consequences - an overview. Atheroscler Suppl 9:63-68

16. Schulze MB, Rimm EB, Shai I, Rifai N, Hu FB (2004) Relationship between adiponectin and glycemic control, blood lipids, and inflammatory markers in men with type 2 diabetes. Diabetes Care $27: 1680-1687$

17. Tsubakio-Yamamoto K, Matsuura F, Koseki M et al (2008) Adiponectin prevents atherosclerosis by increasing cholesterol efflux from macrophages. Biochem Biophys Res Commun 375:390-394

18. Vergès B, Petit JM, Duvillard L et al (2006) Adiponectin is an important determinant of apoA-I catabolism. Arterioscler Thromb Vasc Biol 26:1364-1369

19. Lewis GF, Uffelman KD, Szeto LW, Steiner G (1993) Effects of acute hyperinsulinemia on VLDL triglyceride and VLDL apoB production in normal weight and obese individuals. Diabetes 42:833-842

20. Malmstrom R, Packard CJ, Caslake M et al (1998) Effects of insulin and acipimox on VLDL1 and VLDL2 apolipoprotein B production in normal subjects. Diabetes 47:779-787

21. Brown AM, Gibbons GF (2001) Insulin inhibits the maturation phase of VLDL assembly via a phosphoinositide 3-kinasemediated event. Arterioscler Thromb Vasc Biol 21:1656-1661

22. Sparks JD, Sparks CE, Adeli K (2012) Selective hepatic insulin resistance, VLDL overproduction, and hypertriglyceridemia. Arterioscler Thromb Vasc Biol 32:2104-2112

23. Sparks JD, O’Dell C, Chamberlain JM, Sparks CE (2013) Insulindependent apolipoprotein $\mathrm{B}$ degradation is mediated by autophagy and involves class I and class III phosphatidylinositide 3-kinases. Biochem Biophys Res Commun 435:616-620

24. Karimian PN, Adeli K (2011) Insulin silences apolipoprotein B mRNA translation by inducing intracellular traffic into cytoplasmic RNA granules. Biochemistry 50:6942-6950

25. Altomonte J, Cong L, Harbaran S et al (2004) Foxol mediates insulin action on apoC-III and triglyceride metabolism. J Clin Invest 114:1493-1503

26. Laatsch A, Merkel M, Talmud PJ, Grewal T, Beisiegel U, Heeren J (2009) Insulin stimulates hepatic low density lipoprotein receptorrelated protein 1 (LRP1) to increase postprandial lipoprotein clearance. Atherosclerosis 204:105-111

27. Chait A, Bierman EL, Albers JJ (1979) Low-density lipoprotein receptor activity in cultured human skin fibroblasts. Mechanism of insulin-induced stimulation. J Clin Invest 64:1309-1319

28. Ruotolo G, Parlavecchia M, Taskinen MR et al (1994) Normalization of lipoprotein composition by intraperitoneal insulin in IDDM. Role of increased hepatic lipase activity. Diabetes Care 17:6-12

29. Perret B, Mabile L, Martinez L, Terce F, Barbaras R, Collet X (2002) Hepatic lipase: structure/function relationship, synthesis, and regulation. J Lipid Res 43:1163-1169

30. Riemens SC, van Tol A, Stulp BK, Dullaart RP (1999) Influence of insulin sensitivity and the TaqIB cholesteryl ester transfer protein gene polymorphism on plasma lecithin:cholesterol acyltransferase 
and lipid transfer protein activities and their response to hyperinsulinemia in non-diabetic men. J Lipid Res 40:1467-1474

31. Doucet J, Le Floch JP, Bauduceau B, Verny C (2012) GERODIAB: glycaemic control and 5-year morbidity/mortality of type 2 diabetic patients aged 70 years and older: 1 . Description of the population at inclusion. Diabetes Metab 38:523-530

32. Wang J, Stancakova A, Soininen P et al (2012) Lipoprotein subclass profiles in individuals with varying degrees of glucose tolerance: a population-based study of 9399 Finnish men. J Intern Med 272:562-572

33. Arca M, Pigna G, Favoccia C (2012) Mechanisms of diabetic dyslipidemia: relevance for atherogenesis. Curr Vasc Pharmacol 10:684-686

34. Grundy SM, Brewer HB Jr, Cleeman JI, Smith SC Jr, Lenfant C (2004) Definition of metabolic syndrome: report of the National Heart, Lung, and Blood Institute/American Heart Association conference on scientific issues related to definition. Circulation 109:433-438

35. Axelsen M, Smith U, Eriksson JW, Taskinen MR, Jansson PA (1999) Postprandial hypertriglyceridemia and insulin resistance in normoglycemic first-degree relatives of patients with type 2 diabetes. Ann Intern Med 131:27-31

36. Florez H, Ryder E, Campos G et al (1999) Women relatives of Hispanic patients with type 2 diabetes are more prone to exhibit metabolic disturbances. Invest Clin 40:127-142

37. Ooi EM, Ng TW, Chan DC, Watts GF (2009) Plasma markers of cholesterol homeostasis in metabolic syndrome subjects with or without type-2 diabetes. Diabetes Res Clin Pract 85:310-316

38. Simonen PP, Gylling HK, Miettinen TA (2002) Diabetes contributes to cholesterol metabolism regardless of obesity. Diabetes Care 25:1511-1515

39. Brindisi MC, Guiu B, Duvillard L et al (2012) Liver fat content is associated with an increase in cholesterol synthesis independent of statin therapy use in patients with type 2 diabetes. Atherosclerosis 224:465-468

40. Caballero F, Fernandez A, De Lacy AM, Fernandez-Checa JC, Caballeria J, Garcia-Ruiz C (2009) Enhanced free cholesterol, SREBP-2 and StAR expression in human NASH. J Hepatol 50:789-796

41. Shojaee-Moradie F, Ma Y, Lou S, Hovorka R, Umpleby AM (2013) Prandial hypertriglyceridemia in metabolic syndrome is due to an overproduction of both chylomicron and VLDL triacylglycerol. Diabetes 62:4063-4069

42. Hogue JC, Lamarche B, Tremblay AJ, Bergeron J, Gagne C, Couture P (2007) Evidence of increased secretion of apolipoprotein B-48-containing lipoproteins in subjects with type 2 diabetes. J Lipid Res 48:1336-1342

43. Phillips C, Mullan K, Owens D, Tomkin GH (2006) Intestinal microsomal triglyceride transfer protein in type 2 diabetic and nondiabetic subjects: the relationship to triglyceride-rich postprandial lipoprotein composition. Atherosclerosis 187:57-64

44. Nogueira JP, Maraninchi M, Beliard S et al (2012) Absence of acute inhibitory effect of insulin on chylomicron production in type 2 diabetes. Arterioscler Thromb Vasc Biol 32:1039-1044

45. Annuzzi G, De NC, Iovine C et al (2004) Insulin resistance is independently associated with postprandial alterations of triglyceriderich lipoproteins in type 2 diabetes mellitus. Arterioscler Thromb Vasc Biol 24:2397-2402

46. Duez H, Lamarche B, Valero R et al (2008) Both intestinal and hepatic lipoprotein production are stimulated by an acute elevation of plasma free fatty acids in humans. Circulation 117:2369-2376

47. Adiels M, Matikainen N, Westerbacka J et al (2012) Postprandial accumulation of chylomicrons and chylomicron remnants is determined by the clearance capacity. Atherosclerosis 222:222-228
48. Taskinen MR, Nikkila EA, Kuusi T, Harmo K (1982) Lipoprotein lipase activity and serum lipoproteins in untreated type 2 (insulinindependent) diabetes associated with obesity. Diabetologia 22:46-50

49. Olivieri O, Bassi A, Stranieri C et al (2003) Apolipoprotein C-III, metabolic syndrome, and risk of coronary artery disease. J Lipid Res 44:2374-2381

50. Watanabe N, Taniguchi T, Taketoh H et al (1999) Elevated remnantlike lipoprotein particles in impaired glucose tolerance and type 2 diabetic patients. Diabetes Care 22:152-156

51. Nappo F, Esposito K, Cioffi M et al (2002) Postprandial endothelial activation in healthy subjects and in type 2 diabetic patients: role of fat and carbohydrate meals. J Am Coll Cardiol 39:1145-1150

52. Anderson RA, Evans ML, Ellis GR et al (2001) The relationships between post-prandial lipaemia, endothelial function and oxidative stress in healthy individuals and patients with type 2 diabetes. Atherosclerosis 154:475-483

53. Duvillard L, Pont F, Florentin E, Galland-Jos C, Gambert P, Vergès B (2000) Metabolic abnormalities of apolipoprotein B-containing lipoproteins in non-insulin-dependent diabetes: a stable isotope kinetic study. Eur J Clin Investig 30:685-694

54. Kissebah AH, Alfarsi S, Evans DJ, Adams PW (1982) Integrated regulation of very low density lipoprotein triglyceride and apolipoprotein-B kinetics in non-insulin-dependent diabetes mellitus. Diabetes 31:217-225

55. Ginsberg HN, Zhang YL, Hernandez-Ono A (2005) Regulation of plasma triglycerides in insulin resistance and diabetes. Arch Med Res 36:232-240

56. Malmstrom R, Packard CJ, Caslake M et al (1997) Defective regulation of triglyceride metabolism by insulin in the liver in NIDDM. Diabetologia 40:454-462

57. Adiels M, Boren J, Caslake MJ et al (2005) Overproduction of VLDL1 driven by hyperglycemia is a dominant feature of diabetic dyslipidemia. Arterioscler Thromb Vasc Biol 25:1697-1703

58. Pont F, Duvillard L, Florentin E, Gambert P, Vergès B (2002) Early kinetic abnormalities of apoB-containing lipoproteins in insulinresistant women with abdominal obesity. Arterioscler Thromb Vasc Biol 22:1726-1732

59. Chan DC, Watts GF, Redgrave TG, Mori TA, Barrett PH (2002) Apolipoprotein B-100 kinetics in visceral obesity: associations with plasma apolipoprotein C-III concentration. Metabolism 51:1041-1046

60. Adiels M, Taskinen MR, Packard C et al (2006) Overproduction of large VLDL particles is driven by increased liver fat content in man. Diabetologia 49:755-765

61. Sondergaard E, Sorensen LP, Rahbek I, Gormsen LC, Christiansen JS, Nielsen S (2012) Postprandial VLDL-triacylglycerol secretion is not suppressed in obese type 2 diabetic men. Diabetologia 55:2733-2740

62. Taghibiglou C, Rashid-Kolvear F, Van Iderstine SC et al (2002) Hepatic very low density lipoprotein-ApoB overproduction is associated with attenuated hepatic insulin signaling and overexpression of protein-tyrosine phosphatase 1B in a fructose-fed hamster model of insulin resistance. J Biol Chem 277:793-803

63. Chirieac DV, Collins HL, Cianci J, Sparks JD, Sparks CE (2004) Altered triglyceride-rich lipoprotein production in Zucker diabetic fatty rats. Am J Physiol Endocrinol Metab 287:E42-E49

64. Qiu W, Kohen-Avramoglu R, Rashid-Kolvear F et al (2004) Overexpression of the endoplasmic reticulum 60 protein ER-60 downregulates apoB100 secretion by inducing its intracellular degradation via a nonproteasomal pathway: evidence for an ER-60mediated and $\mathrm{pCMB}$-sensitive intracellular degradative pathway. Biochemistry 43:4819-4831

65. Kuriyama H, Yamashita S, Shimomura I et al (1998) Enhanced expression of hepatic acyl-coenzyme A synthetase and microsomal triglyceride transfer protein messenger RNAs in the obese and 
hypertriglyceridemic rat with visceral fat accumulation. Hepatology 27:557-562

66. Kamagate A, Qu S, Perdomo G et al (2008) FoxO1 mediates insulin-dependent regulation of hepatic VLDL production in mice. $\mathrm{J}$ Clin Invest 118:2347-2364

67. Schwarz JM, Linfoot P, Dare D, Aghajanian K (2003) Hepatic de novo lipogenesis in normoinsulinemic and hyperinsulinemic subjects consuming high-fat, low-carbohydrate and low-fat, highcarbohydrate isoenergetic diets. Am J Clin Nutr 77:43-50

68. Ishii S, Iizuka K, Miller BC, Uyeda K (2004) Carbohydrate response element binding protein directly promotes lipogenic enzyme gene transcription. Proc Natl Acad Sci U S A 101:15597-15602

69. Ferre P, Foufelle F (2007) SREBP-1c transcription factor and lipid homeostasis: clinical perspective. Horm Res 68:72-82

70. Duvillard L, Florentin E, Pont F et al (2011) Endogenous chronic hyperinsulinemia does not increase the production rate of VLDL apolipoprotein B: proof from a kinetic study in patients with insulinoma. J Clin Endocrinol Metab 96:2163-2170

71. Juurinen L, Tiikkainen M, Hakkinen AM, Hakkarainen A, YkiJarvinen H (2007) Effects of insulin therapy on liver fat content and hepatic insulin sensitivity in patients with type 2 diabetes. Am J Physiol Endocrinol Metab 292:E829-E835

72. Taskinen MR, Adiels M, Westerbacka J et al (2011) Dual metabolic defects are required to produce hypertriglyceridemia in obese subjects. Arterioscler Thromb Vasc Biol 31:2144-2150

73. Hegele RA, Ginsberg HN, Chapman MJ et al (2014) The polygenic nature of hypertriglyceridaemia: implications for definition, diagnosis, and management. Lancet Diabetes Endocrinol 2:655-666

74. Garvey WT, Kwon S, Zheng D et al (2003) Effects of insulin resistance and type 2 diabetes on lipoprotein subclass particle size and concentration determined by nuclear magnetic resonance. Diabetes 52:453-462

75. Palmer AM, Nova E, Anil E et al (2005) Differential uptake of subfractions of triglyceride-rich lipoproteins by THP-1 macrophages. Atherosclerosis 180:233-244

76. Stahlman M, Pham HT, Adiels M et al (2012) Clinical dyslipidaemia is associated with changes in the lipid composition and inflammatory properties of apolipoprotein-B-containing lipoproteins from women with type 2 diabetes. Diabetologia 55:1156-1166

77. Hyysalo J, Gopalacharyulu P, Bian H et al (2014) Circulating triacylglycerol signatures in nonalcoholic fatty liver disease associated with the I148M variant in PNPLA3 and with obesity. Diabetes 63:312-322

78. Mamo JC, Szeto L, Steiner G (1990) Glycation of very low density lipoprotein from rat plasma impairs its catabolism. Diabetologia 33:339-345

79. Saheki S, Hitsumoto Y, Murase M, Takeuchi N, Uchida K (1993) In vitro degradation of very low density lipoprotein from diabetic patients by lipoprotein lipase. Clin Chim Acta 217:105-114

80. Stolinski M, Alam S, Jackson NC et al (2008) Effect of 6-month supervised exercise on low-density lipoprotein apolipoprotein B kinetics in patients with type 2 diabetes mellitus. Metabolism 57:1608-1614

81. Duvillard L, Florentin E, Lizard G et al (2003) Cell surface expression of LDL receptor is decreased in type 2 diabetic patients and is normalized by insulin therapy. Diabetes Care 26:1540-1544

82. Witztum JL, Mahoney EM, Branks MJ, Fisher M, Elam R, Steinberg D (1982) Nonenzymatic glucosylation of low-density lipoprotein alters its biologic activity. Diabetes 31:283-291

83. Rabbani N, Chittari MV, Bodmer CW, Zehnder D, Ceriello A, Thornalley PJ (2010) Increased glycation and oxidative damage to apolipoprotein B100 of LDL cholesterol in patients with type 2 diabetes and effect of metformin. Diabetes 59:1038-1045
84. Steinbrecher UP, Witztum JL (1984) Glucosylation of low-density lipoproteins to an extent comparable to that seen in diabetes slows their catabolism. Diabetes 33:130-134

85. Makita T, Tanaka A, Nakano T, Nakajima K, Numano F (1999) Importance of glycation in the acceleration of low density lipoprotein (LDL) uptake into macrophages in patients with diabetes mellitus. Int Angiol 18:149-153

86. Kita T, Kume N, Minami M et al (2001) Role of oxidized LDL in atherosclerosis. Ann N Y Acad Sci 947:199-205

87. Feingold KR, Grunfeld C, Pang M, Doerrler W, Krauss RM (1992) LDL subclass phenotypes and triglyceride metabolism in noninsulin-dependent diabetes. Arterioscler Thromb 12:1496-1502

88. Vakkilainen J, Steiner G, Ansquer JC et al (2003) Relationships between low-density lipoprotein particle size, plasma lipoproteins, and progression of coronary artery disease: the Diabetes Atherosclerosis Intervention Study (DAIS). Circulation 107:1733-1737

89. Tani M, Kawakami A, Mizuno Y et al (2011) Small dense LDL enhances THP-1 macrophage foam cell formation. J Atheroscler Thromb 18:698-704

90. Anber V, Griffin BA, McConnell M, Packard CJ, Shepherd J (1996) Influence of plasma lipid and LDL-subfraction profile on the interaction between low density lipoprotein with human arterial wall proteoglycans. Atherosclerosis 124:261-271

91. Vakkilainen J, Makimattila S, Seppala-Lindroos A et al (2000) Endothelial dysfunction in men with small LDL particles. Circulation 102:716-721

92. Vergès B, Brun JM, Vaillant G et al (1992) Influence of obesity and hypertriglyceridaemia on the low HDL2-cholesterol level and on its relationship with prevalence of atherosclerosis in type 2 diabetes. Diabete Metab 18:289-297

93. Golay A, Zech L, Shi MZ, Chiou YA, Reaven GM, Chen YD (1987) High density lipoprotein (HDL) metabolism in noninsulindependent diabetes mellitus: measurement of HDL turnover using tritiated HDL. J Clin Endocrinol Metab 65:512-518

94. Duvillard L, Pont F, Florentin E, Gambert P, Vergès B (2000) Inefficiency of insulin therapy to correct apolipoprotein A-I metabolic abnormalities in non-insulin-dependent diabetes mellitus. Atherosclerosis 152:229-237

95. Despres JP, Ferland M, Moorjani S et al (1989) Role of hepatictriglyceride lipase activity in the association between intraabdominal fat and plasma HDL cholesterol in obese women. Arteriosclerosis 9:485-492

96. Vergès B, Adiels M, Boren J et al (2014) Interrelationships between the kinetics of VLDL subspecies and HDL catabolism in abdominal obesity: a multicentre tracer kinetic study. J Clin Endocrinol Metab 99:4281-4290

97. Gordon SM, Davidson WS, Urbina EM et al (2013) The effects of type 2 diabetes on lipoprotein composition and arterial stiffness in male youth. Diabetes 62:2958-2967

98. Plomgaard P, Dullaart RP, de Vries R, Groen AK, Dahlbäck B, Nielsen LB (2009) Apolipoprotein M predicts pre-beta-HDL formation: studies in type 2 diabetic and nondiabetic subjects. J Intern Med 266:258-267

99. Karuna R, Park R, Othman A et al (2011) Plasma levels of sphingosine-1-phosphate and apolipoprotein $\mathrm{M}$ in patients with monogenic disorders of HDL metabolism. Atherosclerosis 219:855-863

100. Patel DC, Albrecht C, Pavitt D et al (2011) Type 2 diabetes is associated with reduced ATP-binding cassette transporter A1 gene expression, protein and function. PLoS ONE 6:e22142

101. Passarelli M, Tang C, McDonald TO et al (2005) Advanced glycation end product precursors impair ABCA1-dependent cholesterol removal from cells. Diabetes 54:2198-2205

102. Mauldin JP, Nagelin MH, Wojcik AJ et al (2008) Reduced expression of ATP-binding cassette transporter G1 increases cholesterol 
accumulation in macrophages of patients with type 2 diabetes mellitus. Circulation 117:2785-2792

103. Nobecourt E, Jacqueminet S, Hansel B et al (2005) Defective antioxidative activity of small dense HDL3 particles in type 2 diabetes: relationship to elevated oxidative stress and hyperglycaemia. Diabetologia 48:529-538

104. Persegol L, Vergès B, Foissac M, Gambert P, Duvillard L (2006) Inability of HDL from type 2 diabetic patients to counteract the inhibitory effect of oxidised LDL on endothelium-dependent vasorelaxation. Diabetologia 49:1380-1386

105. Sorrentino SA, Besler C, Rohrer L et al (2010) Endothelialvasoprotective effects of high-density lipoprotein are impaired in patients with type 2 diabetes mellitus but are improved after extended-release niacin therapy. Circulation 121:110-122

106. Bagdade JD, Lane JT, Subbaiah PV, Otto ME, Ritter MC (1993) Accelerated cholesteryl ester transfer in noninsulin-dependent diabetes mellitus. Atherosclerosis 104:69-77

107. Passarelli M, Catanozi S, Nakandakare ER et al (1997) Plasma lipoproteins from patients with poorly controlled diabetes mellitus and "in vitro" glycation of lipoproteins enhance the transfer rate of cholesteryl ester from HDL to apo-B-containing lipoproteins. Diabetologia 40:1085-1093

108. Bouillet B, Gautier T, Blache D et al (2014) Glycation of apolipoprotein $\mathrm{C} 1$ impairs its CETP inhibitory property: pathophysiological relevance in patients with type 1 and type 2 diabetes. Diabetes Care 37:1148-1156

109. Desrumaux C, Athias A, Bessede G et al (1999) Mass concentration of plasma phospholipid transfer protein in normolipidemic, type IIa hyperlipidemic, type IIb hyperlipidemic, and non-insulin-dependent diabetic subjects as measured by a specific ELISA. Arterioscler Thromb Vasc Biol 19:266-275
110. de Vries R, Dallinga-Thie GM, Smit AJ, Wolffenbuttel BH, van Tol A, Dullaart RP (2006) Elevated plasma phospholipid transfer protein activity is a determinant of carotid intima-media thickness in type 2 diabetes mellitus. Diabetologia 49:398-404

111. Zhu W, Cheng KK, Vanhoutte PM, Lam KS, Xu A (2008) Vascular effects of adiponectin: molecular mechanisms and potential therapeutic intervention. Clin Sci (Lond) 114:361-374

112. Cnop M, Havel PJ, Utzschneider KM et al (2003) Relationship of adiponectin to body fat distribution, insulin sensitivity and plasma lipoproteins: evidence for independent roles of age and sex. Diabetologia 46:459-469

113. Ng TW, Watts GF, Farvid MS, Chan DC, Barrett PH (2005) Adipocytokines and VLDL metabolism: independent regulatory effects of adiponectin, insulin resistance, and fat compartments on VLDL apolipoprotein B-100 kinetics? Diabetes 54:795-802

114. Annuzzi G, Bozzetto L, Patti L et al (2010) Type 2 diabetes mellitus is characterized by reduced postprandial adiponectin response: a possible link with diabetic postprandial dyslipidemia. Metabolism 59:567-574

115. Qiao L, Zou C, van der Westhuyzen DR, Shao J (2008) Adiponectin reduces plasma triglyceride by increasing VLDL triglyceride catabolism. Diabetes 57:1824-1833

116. Takebayashi K, Suetsugu M, Wakabayashi S, Aso Y, Inukai T (2007) Retinol binding protein-4 levels and clinical features of type 2 diabetes patients. J Clin Endocrinol Metab 92:2712-2719

117. Vergès B, Guiu B, Cercueil JP et al (2012) Retinol-binding protein 4 is an independent factor associated with triglycerides and a determinant of very low-density lipoprotein-apolipoprotein B100 catabolism in type 2 diabetes mellitus. Arterioscler Thromb Vasc Biol 32:3050-3057 